NURSING PRACTICE

\title{
Effectiveness of a Planned Teaching Program on Knowledge and Skill in the Use of Partograph among Nurses Working in Maternity Unit
}

\author{
${ }^{1}$ Arez Saviola, ${ }^{2}$ Raddi Sudha A, ${ }^{3}$ Metgud MC \\ ${ }^{1}$ KLES Institute of Nursing Sciences, Belgaum, Karnataka, India \\ 2 Professor and HOD, Department of OBG Nursing, KLES Institute of Nursing Sciences, Belgaum, Karnataka, India \\ ${ }^{3}$ Associate Professor, Department of OBG, JNMC, Belgaum, Karnataka, India
}

Correspondence: Arez Saviola, KLES Dr Prabhakar Kore Hospital and Medical Research Center, Nehrunagar Belgaum 590010, Karnataka, India, Phone: 0831-2473777, Fax: 0831-2470732, e-mail: klehosp@satyam.net.in

\begin{abstract}
Objectives: To assess the knowledge and skills of nurses regarding the use of partograph and evaluate the effectiveness of a planned teaching program in the use of partograph among nurses.

Methods: The research approach for the study was that of an evaluative one with one group pre-test post-test design. The study comprised of 30 nurses working in maternity unit of KLES Dr Prabhakar Kore Hospital and Medical Research Center, Belgaum. The tool used for gathering relevant data was a structured questionnaire on knowledge and skill in the use of partograph.

Results: Analysis of data was done on the basis of objectives and hypotheses. It was found that the overall pre-test mean knowledge scores was 13.9, whereas post-test mean knowledge scores was 21.83. The range between highest score and the lowest score in the pre-test was 15 which was decrease to 5 after administration on planned teaching program in the post-test. The overall pre-test mean skill scores was 5.57, whereas post-test mean skill scores was 12.63 . The range between highest scores and lowest scores in the pre-test was 9 which was decrease to 7 after administration of planned teaching program in the post-test.

Conclusion: Based on the analyses of the findings of the study, the following inference was drawn. There was evident increase in the knowledge and scores in all the areas included in the study after administration of planned teaching program. Thus it was inferred that the planned teaching program was effective and while the gain in knowledge and skill score is commendable, there is still room for improvement.
\end{abstract}

\section{INTRODUCTION}

Obstructed labor remains an important cause of not only maternal death but also short and long-term disability. The number of maternal deaths as a result of obstructed labor and/or ruptured uterus varies between 4 to $70 \%$ of all maternal deaths. Prolonged labor in the developing world is commonly due to Cephalopelvic Disproportion (CPD), which may result in obstructed labor. Early detection of abnormal progress of labor would eliminate obstructed labor, uterine rupture and its sequelae. The Partograph is a graphic recording of progress of labor that can be used to detect labor that is not progressing normally and recognize CPD long before labor can become obstructed.

To prevent prolonged labor and its complications, we need a tool which not only prevents prolonged labor, but also identifies the deviation of labor process from normal at the earliest. The Partograph is a simple, inexpensive tool to provide a continuous pictorial over view of labor, detect prolong labor and identify deviation of labor process from normal. Use of partograph during labor can prevent suffering and loss of life. The partograph records the progress of labor, especially the rate of cervical dilatation.

WHO calls for health personnel to use its partograph and its management protocol, both in labor wards with the capabilities to manage labor complications and in health centers without these capabilities can refer women with labor complications to specialist. Having so many benefits attached to the use of partograph, the investigator observed that there is an evident necessity to evaluate the use of partograph among nurses working in maternity unit of KLES Prabhakar Kore Hospital and MRC, Belgaum. The investigator observed that there is a need to improve skills of nurses working in maternity unit in recording the progress of labor and motivate them to maintain partograph for a woman in labor as a routine practice. 
The rationale for advocating such a tool. The partograph is to reduce the time midwives spent on note taking, while enabling them to keep detailed and accurate records so as to permit them to provide emotional support to laboring women. Hence the investigator feels that it is very essential to train the nurses working in maternity unit with knowledge and skill in the use of partograph which will help the nurses to provide a comprehensive intrapartum care to the laboring mothers with early identification and prevention of complication, thereby playing an important role in reducing the maternal mortality and morbidity.

\section{METHODS}

The data were collected from 12th to 19th September 2008 after obtaining permission from hospital authorities. Pre-test was conducted using a structured knowledge questionnaire for 30 mins to assess the knowledge and skill in the use of partograph. Planned teaching program was administered after the pre-test on the use of partograph. Post-test was conducted after 7days.

\section{RESULT}

The findings of the study showed that majority of nurses 23 (76.67\%) belonged to the age group of 20-25 years. Maximum number of nurses 27 (90\%) had GNM qualification. Majority of nurses $15(50 \%)$ had $1-3$ years of total clinical experience. Maximum number of nurses 16(53.33\%) had experienced in Maternity unit below 1 year. Majority of nurses 28(93.33\%) had no exposure to in-service education program (Table 1). Prior to the administration of planned teaching program, the nurses had maximum knowledge (64.67\%) in the area of anatomy and physiology of labor and minimum knowledge (34.79\%) in the area of skill in use of partograph. However, on administration of planned teaching program, the scores showed considerably greater gain (44.17\%) in the area of skill in use of partograph (Table 2). The overall pre-test mean knowledge scores was 13.9 and median was 14; whereas post-test mean knowledge scores was 21.83 and median was 22 . The overall pre-test mean skill scores is 5.57 and median is 5; whereas post-test mean skill scores is 12.63 and median is 13 . In the pre-test majority of nurses 23 (76.67\%) had average knowledge, 4 (13.33\%) had good knowledge 3(10\%) had poor knowledge; whereas in posttest all the nurses $30(100 \%)$ had good knowledge (Table 3). In the skill, majority of nurses 16(53.33\%) had average skill, 10(33.33\%) had poor skill and 4(13.33\%) had good skill, whereas in the post-test most of the nurses 29(96.67\%) had good skill and only 1 (3.33\%) had average skill (Table 4). The calculated paired ' $\mathrm{t}$ ' value $(\mathrm{t}=13.50)$ was greater than tabulated value $(\mathrm{t}=$ 2.045), indicating that the gain in knowledge score is statistically significant at $\mathrm{p}<0.05$ levels. Therefore the planned teaching program was effective to improve the knowledge of nurses.
Table 1: Frequency and percentage distribution of nurses according to sociodemographic variables

$\mathrm{n}=30$

\begin{tabular}{|c|c|c|c|}
\hline S No. & $\begin{array}{l}\text { Sociodemographic } \\
\text { variables }\end{array}$ & Frequency $(f)$ & Percentage (\%) \\
\hline \multirow[t]{4}{*}{1} & Age in years & & \\
\hline & $20-25$ & 23 & 76.67 \\
\hline & $25-30$ & 05 & 16.67 \\
\hline & 30 and above & 02 & 06.67 \\
\hline \multirow[t]{3}{*}{2} & Professional Qualification & & \\
\hline & GNM Nurse & 27 & 90 \\
\hline & Graduate Nurse & 03 & 10 \\
\hline \multirow[t]{4}{*}{3} & Total years of experience & & \\
\hline & $<1$ year & 08 & 26.67 \\
\hline & $1-3$ years & 15 & 50 \\
\hline & $>3$ years & 07 & 23.33 \\
\hline \multirow[t]{4}{*}{4} & Experience in maternity uni & & \\
\hline & $<1$ year & 16 & 53.33 \\
\hline & $1-3$ years & 10 & 33.33 \\
\hline & $>3$ years & 04 & 13.33 \\
\hline \multirow[t]{3}{*}{5} & In-service education program & $\mathrm{n}$ attended & \\
\hline & Yes & 02 & 06.67 \\
\hline & No & 28 & 93.33 \\
\hline
\end{tabular}

Table 2: Pre-test and post-test percentage of mean percentage knowledge and skill scores of nurses in different areas of knowledge

$\begin{array}{lllllll}\text { S } & \begin{array}{l}\text { Areas of } \\ \text { Nonowledge }\end{array} & \begin{array}{l}\text { Total } \\ \text { scores } \\ \text { out of }\end{array} & \begin{array}{l}\text { Total } \\ \text { pre-test } \\ \text { scores }\end{array} & \begin{array}{l}\text { Total } \\ \text { post-test } \\ \text { scores }\end{array} & \begin{array}{l}\text { Pre-test } \\ \text { mean } \\ (\%)\end{array} & \begin{array}{l}\text { Post } \\ \text { test } \\ \text { mean (\%) }\end{array} \\ 1 & \begin{array}{l}\text { Anatomy and } \\ \text { physiology of } \\ \text { labor }\end{array} & 300 & 194 & 270 & 64.67 & 90 \\ 2 & \begin{array}{l}\text { Knowledge of } \\ \text { partograph }\end{array} & 420 & 223 & 385 & 53.81 & 91.67 \\ 3 & \begin{array}{l}\text { Skill in use of } \\ \text { partograph }\end{array} & 480 & 167 & 379 & 34.79 & 78.96 \\ & & & & & & \end{array}$

Table 3: Frequency and percentage distribution of knowledge scores of nurses in the use of partograph

\begin{tabular}{lcrrcc} 
& & \multicolumn{2}{c}{ Pre-test } & \multicolumn{2}{c}{ Post-test } \\
Scores & & Frequency & $\%$ & Frequency & $\%$ \\
Good & $(19-24)$ & 4 & 13.33 & 30 & 100 \\
Average & $(10-18)$ & 23 & 76.67 & - & - \\
Poor & $(1-9)$ & 3 & 10 & - & -
\end{tabular}

Table 4: Frequency and percentage distribution of skill scores of nurses regarding use of partograph

\begin{tabular}{lccccr} 
& & & & & \multicolumn{2}{c}{$\mathrm{n}=30$} \\
Scores & & \multicolumn{2}{c}{ Pre-test } & \multicolumn{2}{c}{ Post-test } \\
& & Frequency & $\%$ & Frequency & $\%$ \\
Good & $(10$ to 16$)$ & 4 & 13.33 & 29 & 96.67 \\
Average & (4 to 9$)$ & 16 & 53.33 & 1 & 3.33 \\
Poor & (1 to 3) & 10 & 33.33 & - & -
\end{tabular}

The calculated paired ' $t$ ' value $(t=13.36)$ was greater than tabulated value $(t=2.045$, indicating that the gain in skills score is statistically significant at $\mathrm{p}<0.05$ levels. Therefore the planned teaching program was effective to improve the skills of nurses. 
The variables professional qualification and in-service education showed an association with pre-test knowledge at 0.05 level of significance. No association was found between the variables and pre-test skill scores at 0.05 level of significance. Karl Pearson's Coefficient of correlation was used to compute the correlation between knowledge and skill and was found to have a positive correlation $\left(\mathrm{r}_{\mathrm{xy}}=0.5714\right)$.

\section{DISCUSSION}

In the present study a sample of 30 nurses working in maternity unit were taken for the study. Findings showed that majority of nurses 23(76.67\%) belonged to the age group of 20-25 years. Similar findings were seen in a study conducted by Deepaty ${ }^{1}$, where majority of nurses 33(73.3\%) belonged to the age group of 20-24 years. Majority of nurses 27 (90\%) had GNM qualification. This finding corresponds with findings of the study of Desai ${ }^{2}$ who had 30 (88\%) diploma nurses as her sample for the study. Majority of nurses $15(50 \%)$ had $1-3$ years of total clinical experience and 8 (26.67\%) had below 1 year of total clinical experience. These findings are similar to the findings of the study of Salunkhe ${ }^{3}$ who had majority of nurses $19(54.3 \%)$ with less than 3 years of total clinical experience and 12 (34.35\%) less than one year of clinical experience. Majority of nurses 16(53.33\%) had experienced in maternity unit below one year and $14(13.33 \%)$ had experienced in maternity unit above one years. The findings are similar to the findings of the study of Salunkhe ${ }^{3}$ where majority of nurses $23(65.7 \%)$ had less than one year of experience in maternity unit and 12(34.3\%) nurses had above one year of experience in maternity unit. The results of the study show that majority of nurses 28(93.33\%) had no exposure to in-service education program and only 02(06.67\%) of nurses had exposure to in-service education program. These findings are similar to the findings of the study of Salunkhe ${ }^{3}$ where majority of nurses 33(94.2\%) who participated in the study had no exposure to in-service education program and Deepaty ${ }^{1}$ where maximum 38 (84.4\%) of nurses had no exposure to inservice education program. The investigator assessed the knowledge and skill of nurses regarding the use of partograph and the findings of the study revealed that majority of nurses $23(76.67 \%)$ had average knowledge, 4 (13.33\%) had good knowledge and 3(10\%) had poor knowledge. The results contradict the findings of Olapado and Daniel ${ }^{4}$ where in a sample of 216 health care personnel, 36(16.7\%), 61(28.2\%) and $119(55.5 \%)$ had demonstrated poor, fair and good levels of knowledge. Knowledge and skill in the use of partograph was assessed and the analysis for association between existing knowledge and skill was done using Chi-square test. There was no association between the variables age, total clinical experience and experience in maternity unit in relation with pretest knowledge scores of nurses, whereas the variables professional qualification and in-service education program showed an association between existing knowledge. The results contradict with the findings of the study of Desai ${ }^{2}$ where there was no association between knowledge of nurses and demographic variables. In the skill aspect of analysis of this study, there was no association found with the demographic variables. No similar studies were found to support or contradict the findings of the study. Karl Pearson's coefficient of correlation was used to compute the correlation between knowledge and skill variables and a positive correlation was found. No studies were found to support or contradict the present study.

\section{REFERENCES}

1. Deepaty GP. A study to evaluate the effectiveness of planned teaching program on the knowledge of active management of third stage of labor in the prevention of postpartum hemorrhage among staff nurses working in the KLES Hospital and MRC, Belgaum, Karnataka 2008.

2. Desai SV. A study to assess the effectiveness of self instructional module (SIM) regarding the knowledge and practices of management of clients on ventilator among nurses working in critical care units of KLES Hospital and MRC, Belgaum 2004.

3. Salunkhe J. A study to evaluate the effectiveness of planned teaching program on the nursing management of first stage of labor among nurses of a selected hospital in Belgaum, Karnataka 2007.

4. Olapado OT, Daniel Olatunji AO. Knowledge and use of partograph among health care personnel at the peripheral maternity centers Nigeria. J Obstet Gynaecol [online] 22006 aug. Available from:URL:http://www.ingentaconnect.com/ content/tandf/cjog/2006, 2007;12;26(6):538-41. 